\title{
Cultivo in vitro da bananeira Prata Anã clone Gorutuba, em meio líquido, agitado e estacionário ${ }^{1}$
}

\author{
Annanda Mendes Costa ${ }^{2 *}$, Renata Aparecida Neres Faria ${ }^{3}$, Luciana Nogueira Londe 4 , \\ Emerson Brito Ribeiro ${ }^{4}$, Nayara de Souza Damascena ${ }^{3}$
}

$10.1590 / 0034-737 X 201663030001$

\begin{abstract}
RESUMO
O objetivo deste trabalho foi avaliar o cultivo in vitro da bananeira Prata Anã (Musa spp.), clone Gorutuba, em diferentes volumes de meio líquido, nos sistemas estacionário e sob agitação, comparando-os com o cultivo tradicional em meio semissólido. O experimento foi conduzido em delineamento inteiramente casualizado, sendo um fatorial 5 × $2+$ 1, com cinco volumes $(10,15,20,25$ e $30 \mathrm{~mL}$ ) de meio líquido e dois sistemas de cultivo (agitação e estacionário) e a testemunha (meio semissólido), com quatro repetições, sendo cada parcela constituída por um frasco com quatro explantes. O número de brotações por explante, observado pela testemunha no terceiro subcultivo, diferiu de alguns tratamentos em meio líquido. No quarto subcultivo, o número de brotações por explante da testemunha diferiu de todos os tratamentos em meio líquido e o sistema de cultivo sob agitação favoreceu um número de brotações por explante significativamente superior ao obtido pelo sistema estacionário. Na fase de alongamento e enraizamento, os resultados verificados em meio líquido foram melhores que os da testemunha. Comparando-se os dois sistemas de cultivo em meio líquido, constatou-se melhor crescimento das plântulas que permaneceram sob agitação com o volume de $30 \mathrm{~mL}$. O cultivo em meio semissólido é mais eficiente na fase de multiplicação in vitro; nas fases de alongamento e de enraizamento, o melhor sistema a ser adotado é o cultivo em meio líquido sob agitação, com o volume de $30 \mathrm{~mL}$.
\end{abstract}

Palavras-chave: Musa spp., micropropagação, meio MS.

\section{ABSTRACT}

\section{In vitro cultivation of "Prata Anã" banana Gorutuba clone in agitated and stationary liquid medium}

The aim of this study was to evaluate the in vitro cultivation of Prata Anã banana Gorutuba clone in different volumes of liquid medium in the stationary system and under agitation, compared with the traditional cultivation in semisolid medium. The experiment was conducted in a completely randomized design with factorial $5 \times 2+1$, with five volumes $(10,15,20,25$ and $30 \mathrm{~mL})$ of liquid medium and two cropping systems (agitation and stationary) and control (semisolid medium), with 4 replicates; each plot had a bottle with 4 explants. The number of shoots/explant observed by the control on the third subculture differs from some treatments in liquid medium. In the fourth subculture, the number of shoots/explant of the control differed from all treatments in liquid medium, and cultivation under agitation system favored a number of shoots/explant significantly higher than that obtained by the stationary system. In the elongation and rooting phases, the results obtained in liquid medium were better than the control. Comparing the two

\footnotetext{
Submetido em 17/08/2014 e aprovado em 07/11/2015

Este trabalho é parte do trabalho de conclusão de curso da primeira autora. Fonte financiadora:Fundação de Amparo à Pesquisa do Estado de Minas Gerais - FAPEMIG

${ }^{2}$ Universidade Federal de Viçosa, Viçosa, Minas Gerais, Brasil. annanda14@gmail.com

${ }^{3}$ Universidade Estadual de Montes Claros, Janaúba, Minas Gerais, Brasil. renataapneres@gmail.com; nayasouza22@ hotmail.com

Empresa de Pesquisa Agropecuária de Minas Gerais, Nova Porteirinha, Minas Gerais, Brasil. luciana@epamig.br; britorib@hotmail.com

*Autor para correspondência: annanda14@gmail.com
} 
systems of cultivation in liquid medium, we noted greater growth of the plantlets, which remained under agitation with the volume of $30 \mathrm{ml}$. The cultivation in semisolid medium is more efficient in the multiplication phase in vitro, and in the elongation and rooting phases, the best system to be adopted is the cultivation in liquid medium under agitation with $30 \mathrm{~mL}$ volume.

Key words: Musa spp.; micropropagation; MS medium.

\section{INTRODUÇÃO}

A micropropagação é umas das técnicas de cultivo in vitro que tem maior impacto para a agricultura, pois permite uma rápida multiplicação de plantas (Ulisses et al., 2010). Segundo Álvares \& Caldas (2002), a micropropagação mediante a cultura de ápices caulinares in vitro tem sido adotada em muitos países para a produção de mudas de bananeira. Entre as frutíferas, a banana é uma das espécies mais micropropagadas no Brasil. Em 2010 foram produzidas, aproximadamente 7,5 milhões de mudas de bananeira, por cultura de tecidos (Carvalho et al., 2011), e o número de biofábricas dedicadas à produção de mudas de banana vem crescendo a cada ano. Em 2012, havia 91,7\% a mais do que no ano de 2008 (Carvalho et al., 2012). No entanto, uma das principais limitações para maior expansão das mudas micropropagadas, no Brasil, entre os produtores, é o elevado custo desses materiais, em comparação com o das mudas obtidas pelos métodos convencionais, que, além de favorecerem a disseminação de doenças e pragas, apresentam baixa taxa de multiplicação (Roels et al., 2005).

A micropropagação utiliza meios nutritivos durante o processo de cultivo in vitro, que fornecem substâncias essenciais para o crescimento dos tecidos e controlam, em grande parte, o padrão de desenvolvimento (Caldas et al., 1998). Os meios nutritivos suprem as exigências das plantas com nutrientes minerais e compostos orgânicos adicionados ao meio, sendo que a consistência do meio pode ser líquida ou sólida, havendo, normalmente, para meio líquido, exigência de algum tipo de suporte ou agitação que promova a oxigenação para respiração do material vegetal (Ulisses et al., 2010). No entanto, o custo com reagentes e com equipamentos para o preparo dos meios é um dos principais fatores que oneram o preço final das mudas, o que justifica a realização de trabalhos que busquem otimizar cada vez mais o protocolo de micropropagação das mudas de bananeira.

Uma das estratégias para o cultivo in vitro, segundo Camolesi et al. (2010), está relacionada com a consistência do meio de cultivo, que pode ser um dos fatores a contribuir para diminuição dos custos. A utilização de meio líquido tem proporcionado resultados iguais ou até melhores que a do meio semissólido, para várias espécies vegetais, como bromélias (Mengarda et al., 2009), cana-de-açúcar
(Cidade et al., 2006), abacaxi (Oliveira et al., 2007), e banana (Andrade et al., 2011). Todavia, espécies e cultivares necessitam de protocolos específicos, pois podem apresentar resultados diferentes sob a mesma condição de cultivo (Fortes \& Pereira, 2001). O cultivo em meio líquido pode proporcionar maior eficiência ao processo de micropropagação, pela facilidade de preparo e pela possibilidade de se usar menor quantidade de meio de cultura (Pereira \& Fortes, 2003). Além disso, o uso de meio nutritivo líquido permite maior contato do material vegetativo com o meio, proporcionando incremento de produtividade e de eficiência, no processo de propagação (Penchel et al., 2007).

O objetivo deste trabalho foi avaliar o cultivo in vitro da bananeira Prata Anã, clone Gorutuba, em diferentes volumes de meio líquido, nos sistemas estacionário e sob agitação, comparando-os com o cultivo tradicional em meio semissólido.

\section{MATERIAL E MÉTODOS}

As mudas da bananeira Prata Anã, clone Gorutuba, foram coletadas na Fazenda Experimental do Gorutuba, da Empresa de Pesquisa Agropecuária de Minas Gerais (EPAMIG), de Nova Porteirinha, MG, e o estudo foi conduzido no Laboratório de Biotecnologia da EPAMIG. Os meristemas apicais, com aproximadamente, $6 \mathrm{~cm}$ de comprimento e $3 \mathrm{~cm}$ de diâmetro, foram estabelecidos em frascos de $320 \mathrm{~mL}$, preenchidos com $30 \mathrm{~mL}$ de meio de cultura semissólido, contendo sais e vitaminas do meio MS (Murashige \& Skoog, 1962), com $30 \mathrm{~g} \mathrm{~L}^{-1}$ de sacarose, $7 \mathrm{~g}$ $\mathrm{L}^{-1}$ de ágar, 2,5 $\mathrm{g} \mathrm{L}^{-1}$ de carvão ativado, 7,0 $\mathrm{mg} \mathrm{L}^{-1}$ de 6benzilaminopurina (BAP), com pH ajustado para 5,7 antes da autoclavagem. O material permaneceu no escuro por sete dias, em seguida, foi submetido a um fotoperíodo de 16 horas e temperatura de $25 \pm 1^{\circ} \mathrm{C}$, na sala de crescimento.

Até o $2^{\circ}$ subcultivo, realizaram-se repicagens dos explantes a cada 30 dias, transferindo-os para o meio MS suplementado com $3 \mathrm{mg} \mathrm{L}^{-1}$ de BAP, $30 \mathrm{~g} \mathrm{~L}^{-1}$ de sacarose $\mathrm{e}$ $7 \mathrm{~g} \mathrm{~L}^{-1}$ de ágar, para multiplicação vegetativa do material. No $3^{\circ}$ e $4^{\circ}$ subcultivo, os explantes foram retirados do meio e os brotos foram excisados e estabelecidos em frascos de $320 \mathrm{~mL}$, com altura de $12,5 \mathrm{~cm}$, diâmetro interno superior do frasco de $5 \mathrm{~cm}$ e espessura de $3 \mathrm{~mm}$. Os tratamentos 
consistiram em diferentes volumes de meio líquido MS $(10,15,20,25$ e $30 \mathrm{~mL})$, suplementado com $30 \mathrm{~g} \mathrm{~L}^{-1} \mathrm{de}$ sacarose, $3 \mathrm{mg} \mathrm{L}^{-1}$ de BAP, com pH ajustado para 5,7, mantidos sem (estacionário) e com agitação contínua, por meio de um shaker com agitação orbital, da marca CIENTEC, modelo CT-712 (50 rpm). A testemunha consistiu em tratamento adicional com um volume de $30 \mathrm{~mL}$ de meio $\mathrm{MS}$, solidificado com ágar $7 \mathrm{~g} \mathrm{~L}^{-1}$, adicionado com $30 \mathrm{~g} \mathrm{~L}^{-1} \mathrm{de}$ sacarose, $3 \mathrm{mg} \mathrm{L}^{-1}$ de BAP, com $\mathrm{pH}$ ajustado para 5,7. A cada 20 dias, realizaram-se a subdivisão longitudinal dos explantes e a transferência para um novo meio com a mesma composição. Ao final da etapa de multiplicação (5º subcultivo), as plântulas foram retiradas do meio, foi feita a limpeza das partes oxidadas, em seguida, as plântulas foram transferidas para o meio de alongamento e enraizamento ( $6^{\circ}$ subcultivo), contendo os sais do meio MS, suplementado com 0,1 mg L-1 de ANA (ácido naftaleno acético) e 2,5 $\mathrm{g} \mathrm{L}^{-1}$ de carvão ativado, sendo mantidos os mesmos tratamentos da fase de multiplicação.

O delineamento experimental foi inteiramente casualizado, em esquema fatorial $5 \times 2+1$, cinco volumes $(10,15,20$, 25 e $30 \mathrm{~mL}$ ) de meio líquido $\mathrm{x}$ dois sistemas: agitado e estacionário) + testemunha (meio semissólido), com quatro repetições, sendo cada parcela constituída por um frasco com quatro explantes.

A cada 20 dias após o $3^{\circ}$ e o $4^{\circ}$ subcultivo, avaliou-se o número de brotos por explante, contando-se em cada explante o número de brotos formados. Após 20 dias do sexto subcultivo, foram avaliados o comprimento da parte aérea e o diâmetro do pseudocaule, com paquímetro digital (Western Pro DC-6), sendo o comprimento da parte aérea medido da base do pseudocaule até a roseta foliar e o diâmetro medido na base do pseudocaule. O número de folhas e de raízes foi avaliado, contando-se aritmeticamente suas respectivas quantidades. As matérias frescas de parte aérea e de raízes foi obtida por pesagem, utilizandose a balança digital analítica (BioPrecisa JH 2102).

Os dados foram submetidos à análise de variância e as médias comparadas pelo teste $\mathrm{F}$, a $5 \%$ de significância. A análise de regressão foi conduzida para as interações significativas dos volumes de meio líquido com os fatores (estacionário e agitado), com o desdobramento dos diferentes volumes de meio dentro de cada sistema de cultivo. Para a comparação das médias dos tratamentos em relação à testemunha, utilizou-se o teste de Dunnett, a 5\% de significância. As análises foram realizadas, utilizando-se o software estatístico SISVAR 5.3 (Ferreira, 2010) e Action 2.6.

\section{RESULTADOS E DISCUSSÃO}

Na fase de multiplicação do terceiro subcultivo, não houve diferenças significativas no número de brotações por explante para os fatores isolados nem para a interação dos volumes com os sistemas de cultivo utilizados. No entanto, a testemunha (semissólido), quando comparada com os volumes 10 e $20 \mathrm{~mL}$ sob agitação e 20,25 e $30 \mathrm{~mL}$ no sistema estacionário, obteve resultado estatisticamente superior, com 2,69 brotos por explante (Tabela 1). O número de brotações por explante da testemunha (semissólido), no quarto subcultivo, foi estatisticamente superior aos produzidos pelos tratamentos em meio líquido, nos dois sistemas de cultivos, independentemente do volume (Tabela 2). A maior taxa de multiplicação, no terceiro e quarto subcultivo em meio semissólido pode ser explicada pelo fato de os explantes ainda pequenos ficarem imersos em meio líquido, o que não permite oxigenação suficiente para o bom desempenho da multiplicação celular, mesmo com agitação. Esses resultados corroboram os obtidos por Costa et al. (2007), os quais observaram maior taxa de multiplicação ( 4,8 brotos/explante) para o cultivar Grande Naine, ao utilizarem meio semissólido gelificado com ágar, do que com o meio sem solidificante, de consistência líquida (estacionário) (2,0 brotos/explante), após três subcultivos. Já Camolesi et al. (2010), comparando o meio semissólido com o meio líquido estacionário para banana 'Maçã', no quarto subcultivo, não notaram diferença significativa no número de brotações, ao utilizarem frasco de $250 \mathrm{~mL}$, com $40 \mathrm{~mL}$ de meio de cultura. Siqueira et al. (2013) não observaram diferença significativa na taxa de multiplicação, ao trabalharem com diferentes volumes de meio de cultura líquido estacionário, comparado com o cultivo em meio semissólido para banana 'Maçã'. Foi observado, ainda na fase de multiplicação, um coeficiente de variação maior, no terceiro subcultivo $(38,63)$, que diminuiu em seguida, no quarto subcultivo $(26,12)$, o que pode ser explicado pelo fato de os explantes no terceiro subcultivo serem transferidos do cultivo em meio semissólido para o cultivo em meio líquido, tendo o material vegetal demorado a se estabilizar no novo sistema de cultivo.

No quarto subcultivo, não houve efeito significativo para a interação dos volumes de meio de cultura com os sistemas de cultivo; também não foram observadas diferenças significativas entre os volumes de meio utilizados; todavia, o sistema de cultivo em meio líquido sob agitação, quando comparado com o cultivo estacionário, favoreceu uma maior multiplicação in vitro, significativamente superior (Tabela 2). Pereira \& Fortes (2003) obtiveram maiores taxas de multiplicação com cultivares de batata, no cultivo em meio líquido com agitação por 24 horas, do que em cultivo em meio líquido, sem agitação. Segundo Alvard et al. (1993) e Grattapaglia \& Machado (1998), o cultivo em meio líquido requer um suporte que promova a agitação para o fornecimento do oxigênio necessário para a formação de brotos. Cidade et al. (2006) obtiveram maiores taxas de multiplicação in vitro, de cana-de-açúcar, em cultura 
líquida com agitação do que com culturas líquidas sem agitação e cultura em meio semissólido.

Nas fases de alongamento e de enraizamento, a testemunha diferiu de todos os tratamentos cultivados em meio líquido sob agitação, para a variável analisada comprimento da parte aérea, e obtiveram-se resultados superiores aos da testemunha (Tabela 3). Debiasi et al. (2002) afirmam que a média de proliferação de brotos é inversamente proporcional ao tamanho que esses apresentam, o que pode explicar os resultados inferiores, especialmente no comprimento da parte aérea da testemunha, que obteve mais sucesso no número de brotações e foi inferior nos resultados de comprimento, em comparação com os demais sistemas. De acordo com Mehrotra et al. (2007), o meio líquido permite o contato próximo com o tecido, o que estimula e facilita a absorção de nutrientes e de reguladores de crescimento, levando ao melhor desenvolvimento de parte aérea e ao crescimento radicular.
Quanto ao diâmetro do pseudocaule, os tratamentos dos dois sistemas de cultivo diferiram do da testemunha, obtendo-se valores superiores, exceto no tratamento com volume de $30 \mathrm{~mL}$ do cultivo estacionário. Para a avaliação do número de folhas, os volumes 10, 20 e $30 \mathrm{~mL}$ do sistema de cultivo em meio líquido, sob agitação, e os volumes 15 e $20 \mathrm{~mL}$, no cultivo estacionário, diferiram da testemunha, alcançando melhores resultados (Tabela 3). Nenhum tratamento dos sistemas de cultivos de meio líquido diferiu da testemunha em relação ao número de raízes; já, para matéria fresca da parte aérea, os volumes 15, 20, 25 e $30 \mathrm{~mL}$, sob agitação, e 15 e 20 mL, no sistema estacionário, obtiveram resultados significativamente superiores aos da testemunha. Para matéria fresca de raízes, os volumes 25 e $30 \mathrm{~mL}$, no sistema estacionário, apresentaram diferença significativa em relação à testemunha, com resultados inferiores (Tabela 3). De acordo Lemos et al. (2001), há um melhor aproveitamento do meio de cultura quando se utiliza meio

Tabela 1. Número de brotações por explante da bananeira Prata Anã, clone Gorutuba, cultivada em diferentes volumes de meio líquido, nos sistemas estacionário e sob agitação, comparado com o cultivo em meio semissólido, no $3^{\circ}$ subcultivo in vitro

\begin{tabular}{lccc}
\hline \multirow{2}{*}{ Volume $(\mathbf{m L})$} & \multicolumn{2}{c}{ Número de brotações/explante } & \multirow{2}{*}{ Média } \\
\cline { 2 - 3 } & \multicolumn{2}{c}{ Sistemas de cultivo } & \multicolumn{1}{c}{ Estacionário } \\
\cline { 2 - 3 } 10 & Agitação & 1,44 & $1,62 \mathrm{a}$ \\
15 & $1,00^{*}$ & 1,44 & $1,31 \mathrm{a}$ \\
20 & 1,81 & $1,25^{*}$ & $1,37 \mathrm{a}$ \\
25 & $1,38^{*}$ & $1,31^{*}$ & $1,62 \mathrm{a}$ \\
30 & 1,44 & $1,00^{*}$ & \\
\hline Média & 2,25 & $1,28 \mathrm{~A}$ & \\
\hline
\end{tabular}

TESTEMUNHA (meio semissólido) $\quad \mathrm{N}^{\circ}$ de brotações/explante $=2,69$

\begin{tabular}{cc}
$\mathrm{CV}(\%)$ & 38,63 \\
\hline
\end{tabular}

Médias seguidas por letras distintas, minúsculas na coluna e maiúsculas na linha, diferem entre si pelo teste $\mathrm{F}$ a $5 \%$ de significância.

Médias seguidas por * diferem da testemunha pelo teste de Dunnet a $5 \%$ de significância.

Tabela 2. Número de brotações por explante da bananeira Prata Anã, clone Gorutuba, cultivada em diferentes volumes de meio líquido, nos sistemas estacionário e sob agitação, comparado com o cultivo em meio semissólido, no $4^{\circ}$ subcultivo in vitro

\begin{tabular}{|c|c|c|c|}
\hline \multirow{3}{*}{ Volume $(\mathbf{m L})$} & \multicolumn{2}{|c|}{ Número de brotações/explante } & \multirow{3}{*}{ Média } \\
\hline & \multicolumn{2}{|c|}{ Sistemas de cultivo } & \\
\hline & Agitação & Estacionário & \\
\hline 10 & $1,69 *$ & $1,63^{*}$ & $1,66 \mathrm{a}$ \\
\hline 15 & $2,38 *$ & $1,56^{*}$ & $1,97 \mathrm{a}$ \\
\hline 20 & $1,94^{*}$ & $1,50^{*}$ & $1,72 \mathrm{a}$ \\
\hline 25 & $1,88^{*}$ & $1,31^{*}$ & $1,59 \mathrm{a}$ \\
\hline 30 & $2,31 *$ & $1,00^{*}$ & $1,65 \mathrm{a}$ \\
\hline Média & $2,04 \mathrm{~A}$ & $1,4 \mathrm{~B}$ & \\
\hline
\end{tabular}

TESTEMUNHA (meio semissólido) $\quad \mathrm{N}^{\circ}$ de brotações/explante $=3,50$

$\mathrm{CV}(\%) \quad 26,12$

Médias seguidas por letras distintas, minúsculas na coluna e maiúsculas na linha, diferem entre si pelo teste $\mathrm{F}$ a $5 \%$ de significância.

Médias seguidas por * diferem da testemunha pelo teste de Dunnet a 5\% de significância.

Rev. Ceres, Viçosa, v. 63, n.3, p. 277-281, mai/jun, 2016 
Tabela 3. Comprimento da parte aérea, diâmetro do pseudocaule, número de folhas, número de raízes, matéria fresca da parte aérea, matéria fresca da raiz da bananeira Prata Anã, clone Gorutuba, cultivada em diferentes volumes de meio líquido, nos sistemas estacionário e sob agitação, comparado com o cultivo em meio semissólido, ao final do último subcultivo in vitro (alongamento e enraizamento)

\begin{tabular}{lccccccc}
\hline Meio & Volume & $\begin{array}{c}\text { Comprimento } \\
\text { da parte aérea } \\
(\mathbf{m m})\end{array}$ & $\begin{array}{c}\text { Diâmetro do } \\
\text { pseudocaule } \\
(\mathbf{m m})\end{array}$ & $\begin{array}{c}\mathbf{N}^{\mathbf{0}} \text { de } \\
\text { folhas }\end{array}$ & $\begin{array}{c}\mathbf{N}^{\mathbf{0}} \text { de } \\
\text { raízes }\end{array}$ & $\begin{array}{c}\text { Matéria fresca } \\
\text { da parte aérea } \\
(\mathbf{g})\end{array}$ & $\begin{array}{c}\text { Matéria } \\
\text { fresca da raiz } \\
(\mathbf{g})\end{array}$ \\
\hline & 10 & $28,96^{*}$ & $4,50^{*}$ & $3,42^{*}$ & 1,75 & 0,70 & 0,34 \\
Agitação & 15 & $28,82^{*}$ & $4,94^{*}$ & 3,25 & 1,17 & $0,85^{*}$ & 0,32 \\
& 20 & $30,01^{*}$ & $4,96^{*}$ & $4,00^{*}$ & 2,00 & $1,05^{*}$ & 0,50 \\
& 25 & $34,95^{*}$ & $5,14^{*}$ & 3,31 & 2,00 & $1,16^{*}$ & 0,47 \\
Média & 30 & $41,12^{*}$ & $5,97^{*}$ & $4,38^{*}$ & 2,50 & $1,40^{*}$ & 0,63 \\
& & $32,77 \mathrm{a}$ & $5,10 \mathrm{a}$ & $3,67 \mathrm{a}$ & $1,88 \mathrm{a}$ & $1,03 \mathrm{a}$ & $0,45 \mathrm{a}$ \\
Estacionário & 10 & 19,37 & $4,33^{*}$ & 3,11 & 1,58 & 0,58 & 0,45 \\
& 15 & 23,97 & $4,59^{*}$ & $3,54^{*}$ & 1,92 & $0,81^{*}$ & 0,53 \\
& 20 & 19,93 & $4,89^{*}$ & $3,38^{*}$ & 1,38 & $0,73^{*}$ & 0,23 \\
Média & 25 & 16,73 & $4,45^{*}$ & 2,56 & 1,13 & 0,61 & $0,15^{*}$ \\
Testemunha & 30 & 15,26 & 3,86 & 2,39 & 1,19 & 0,45 & $0,12^{*}$ \\
(meio semissólido) & 30 & $19,05 \mathrm{~b}$ & $4,42 \mathrm{~b}$ & $3,00 \mathrm{~b}$ & $1,44 \mathrm{~b}$ & $0,64 \mathrm{~b}$ & $0,30 \mathrm{~b}$ \\
\hline CV (\%) & 17,75 & 2,99 & 2,53 & 2,50 & 0,41 & 0,42 \\
\hline
\end{tabular}

Médias seguidas por * diferem da testemunha pelo teste de Dunnet a 5\% de significância.

Médias seguidas por letras distintas, minúsculas na coluna, diferem entre si pelo teste F a 5\% de significância.

líquido, tanto em imersão temporária como em permanente, pois aumenta área de contato do explante com o meio, o que favorece a maior absorção de nutrientes e de água por todas as partes. Dessa forma, as características avaliadas mostraram que o desenvolvimento das plântulas, no último subcultivo in vitro, obteve mais sucesso nos sistemas de cultivo em meio líquido do que no cultivo em meio de cultura semissólido. Resultados semelhantes também foram obtidos por Andrade et al. (2011), ao avaliarem o desenvolvimento de cultivares de bananeiras 'Grande Naine' e 'Prata Anã', na fase de enraizamento, em diferentes doses de ágar, e concluíram que não há necessidade do uso de ágar na composição do meio de cultura, quando micropropagadas em laboratório.

Os resultados superiores obtidos nas fases de alongamento e de enraizamento, no sistema de cultivo em meio líquido, sob agitação, quando comparados com os do sistema de cultivo em meio estacionário, devem-se principalmente à distribuição uniforme de nutrientes e à oxigenação fornecida nesse sistema, por meio da agitação (Muhammad et al., 2007). Pereira \& Fortes (2003) também observaram melhores resultados para crescimento de material de batata, em meio líquido, com agitação contínua, do que em meio líquido sem agitação.

De acordo com o teste $\mathrm{F}$ ( $\mathrm{p}<0,05)$, houve efeito significativo na interação entre os diferentes volumes e os dois sistemas de cultivo em meio líquido, para todas as caracte- rísticas avaliadas, nas fases de alongamento e de enraizamento (Figura 1).

A equação representativa do comprimento da parte aérea (Tabela 4) para o cultivo em agitação, em função dos volumes de meio de cultura (Figura 1A), apresentou um ponto de mínimo, no qual, a partir da sua derivação, o volume $13,48 \mathrm{~mL}$ de meio de cultura proporcionou um comprimento mínimo das plântulas de $28,45 \mathrm{~mm}$ e o maior volume $(30 \mathrm{~mL})$ foi o responsável pelo maior comprimento $(41,19$ $\mathrm{mm}$ ). Já no cultivo estacionário, houve um efeito linear do comprimento da parte aérea das plântulas, sendo que o menor volume $(10 \mathrm{~mL})$ alcançou o melhor resultado $(22,14$ $\mathrm{mm})$.

O diâmetro do pseudocaule, no cultivo sob agitação, aumentou linearmente com o incremento dos volumes (Figura 1B); já no cultivo estacionário, houve um efeito quadrático, obtendo-se a partir da derivação, o maior diâmetro $(4,78 \mathrm{~mm})$ com o volume de $18,46 \mathrm{~mL}$.

Como mostra a Figura $1 \mathrm{C}$, à medida que se aumentam os volumes do meio de cultura, há um incremento do número de folhas no cultivo sob agitação e no cultivo estacionário e a derivação do modelo quadrático de regressão mostrou que o volume $15,48 \mathrm{~mL}$ favorece o maior número de folhas $(3,37)$. Em relação ao número de raízes (Figura 1D), para os dois sistemas de cultivo, observou-se um efeito linear, no qual o número de raízes para o cultivo sob agitação cresceu linearmente com o incremento dos volu- 
mes de meio de cultura e, no outro sistema, notou-se um comportamento contrário, com o decréscimo linear.

A matéria fresca da parte aérea (Figura 1E) foi maior no cultivo sob agitação, no qual se notou um comportamento linear crescente, em função do acréscimo dos volumes, ao contrário do cultivo estacionário, em que houve uma cur-


va quadrática, sendo que, no volume $18,65 \mathrm{~mL}$ obtém-se a maior massa $(0,78 \mathrm{~g})$, conforme a derivação da equação, decrescendo em seguida com o aumento do volume. Já a matéria fresca de raízes (Figura 1F) cresceu linearmente com o incremento dos volumes, para o cultivo sob agitação, e decresceu linearmente com o incremento dos volu-
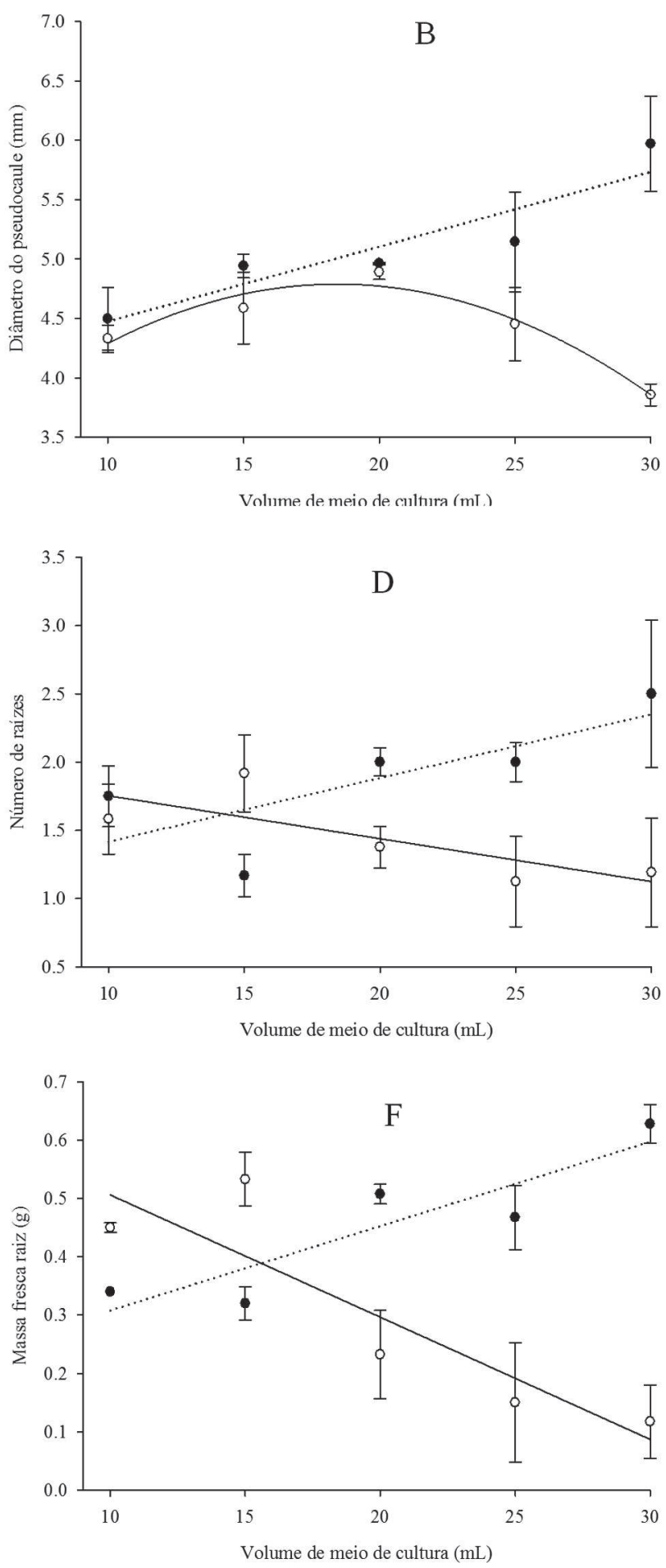

Figura 1. Gráficos de dispersão, acompanhados do erro padrão, obtidos a partir de quatro repetições e de curvas de regressão para comprimento da parte aérea (A), diâmetro do pseudocaule (B), número de folhas (C),número de raízes (D), matéria fresca da parte aérea (E) e matéria fresca de raízes (F), em bananeira cv. Prata Anã, clone Gorutuba, em função de volumes de meio líquido no sistema estacionário (o__) e sob agitação (•......). 
Tabela 4. Equações de regressão referentes a comprimento da parte aérea, diâmetro do pseudocaule, número de folhas, número de raízes, matéria fresca da parte aérea, matéria fresca de raízes da bananeira Prata Anã, clone Gorutuba, cultivada em diferentes volumes de meio líquido, nos sistemas estacionário e sob agitação, comparado com o cultivo em meio semissólido, ao final do último subcultivo in vitro (alongamento e enraizamento).

\begin{tabular}{|c|c|c|}
\hline \multicolumn{3}{|c|}{ Regressões } \\
\hline Comprimento da parte aérea & $\begin{array}{l}\text { Agitação: } \mathrm{y}=36,9555^{*} *-1,2610^{\mathrm{ns}} \mathrm{x}+0,04675^{*} \mathrm{x}^{2} \\
\text { Estacionário: } \mathrm{y}=25,2325 * *-0,30905^{*} \mathrm{x}\end{array}$ & $\begin{array}{l}\mathrm{r}^{2}=99,69 \% \\
\mathrm{R}^{2}=53,29 \%\end{array}$ \\
\hline Diâmetro do pseudocaule & $\begin{array}{l}\text { Agitação: } y=3,8450 * *+0,0629 * * x \\
\text { Estacionário: } y=2,4105 *+0,2578 * x-0,00698 * x^{2}\end{array}$ & $\begin{array}{l}\mathrm{R}^{2}=85,05 \% \\
\mathrm{r}^{2}=94,64 \%\end{array}$ \\
\hline Número de folhas & $\begin{array}{l}\text { Agitação: } y=2,8800 * *+0,03955^{* *} \mathrm{x} \\
\text { Estacionário: } \mathrm{y}=2,1045^{*}+0,1641^{\mathrm{ns}} \mathrm{x}-0,0053 * \mathrm{x}^{2}\end{array}$ & $\begin{array}{l}\mathrm{R}^{2}=40,15 \% \\
\mathrm{r}^{2}=82,26 \%\end{array}$ \\
\hline Número de raízes & $\begin{array}{l}\text { Agitação: } y=0,9505^{*}+0,04665^{*} \mathrm{x} \\
\text { Estacionário: } \mathrm{y}=2,0680^{* *}-0,03145^{\text {ns }} \mathrm{x}\end{array}$ & $\begin{array}{l}\mathrm{R}^{2}=58,02 \% \\
\mathrm{R}^{2}=59,92 \%\end{array}$ \\
\hline Matéria fresca da parte aérea & $\begin{array}{l}\text { Agitação: } y=0,3480 *+0,0342 * * x \\
\text { Estacionário: } y=-0,0110^{\text {ns }}+0,0858 * x-0,0023 * x^{2}\end{array}$ & $\begin{array}{l}\mathrm{R}^{2}=99,02 \% \\
\mathrm{r}^{2}=89,96 \%\end{array}$ \\
\hline Matéria fresca da raiz & $\begin{array}{l}\text { Agitação: } \mathrm{y}=0,1635^{*}+0,01445^{* *} \mathrm{x} \\
\text { Estacionário: } \mathrm{y}=0,7155^{* *}-0,0209^{* *} \mathrm{x}\end{array}$ & $\begin{array}{l}\mathrm{R}^{2}=81,45 \% \\
\mathrm{R}^{2}=80,18 \%\end{array}$ \\
\hline
\end{tabular}

mes para o cultivo estacionário, sendo o menor volume (10 $\mathrm{mL}$ ) o melhor para o cultivo estacionário e o maior volume (30 $\mathrm{mL})$ proporcionou melhores resultados para o cultivo sob agitação. Conforme Pereira et al. (2006), o maior volume de meio diminui a competição, pois disponibiliza mais nutrientes para as plântulas, o que justifica os melhores resultados com o volume de $30 \mathrm{~mL}$, para o cultivo sob agitação. Comportamento diferente foi observado no cultivo estacionário, pois à medida que se aumentam os volumes, nota-se que o desenvolvimento das plântulas diminui, por causa da maior imersão do material vegetal, o que diminui a oxigenação. Siqueira et al. (2013) verificaram que até o volume de $25 \mathrm{~mL}$ de meio líquido estacionário há um incremento de matéria fresca total da microplanta de banana 'Maçã'.

Os resultados obtidos neste estudo permitem inferências sobre uma alternativa de cultivo in vitro nos laboratórios de micropropagação de banana, em que pode ser adotado, na fase de multiplicação, o meio semissólido e, nas fases de alongamento e de enraizamento, o meio líquido sob agitação, a fim de favorecer uma maior quantidade de mudas produzidas in vitro, que apresentem maior vigor, quando forem levadas para a fase de aclimatização.

Embora o cultivo em meio líquido agitado proporcione maior crescimento das plântulas, novos trabalhos devem ser realizados, para elucidar se há necessidade de agitação contínua, podendo haver a possibilidade de intervalos de tempos de agitação para as fases de alongamento e de enraizamento.

\section{CONCLUSÕES}

A multiplicação in vitro de bananeira 'Prata Anã', clone Gorutuba, é maior no cultivo semissólido. Esse resultado indica que o cultivo em meio líquido requer um suporte que promova a agitação mais eficiente, para o fornecimento do oxigênio necessário para a formação de brotos.

O cultivo in vitro em meio líquido sob agitação, com o volume de $30 \mathrm{~mL}$ de meio de cultura, nas fases de alongamento e de enraizamento de bananeira 'Prata Anã', clone Gorutuba, favorece o maior crescimento das plântulas, principalmente por causa da distribuição uniforme de nutrientes e da oxigenação fornecida, nesse sistema, por meio da agitação, que foi suficiente para o alogamento das plântulas.

\section{AGRADECIMENTOS}

Os autores agradecem à Empresa de Pesquisa Agropecuária de Minas Gerais - EPAMIG e à Fundação de Amparo à Pesquisa do Estado de Minas Gerais FAPEMIG.

\section{REFERÊNCIAS}

Action (2013) Estatcamp. Versão 2.6. Disponível em: <www.portalaction.com.br>. Acessado em: 22 de abril de 2014.

Alvard D, Cote F \& Teisson C (1993) Comparison of methods of liquid medium cultures for banana micropropagation: Effect of temporary immersion of explants. Plant Cell, Tissue and Organ Culture, 32:55-60.

Álvares MC \& Caldas LS (2002) Crescimento, produção e variação somaclonal em bananeiras micropropagadas. Pesquisa Agropecuária Brasileira, 37: 415-420.

Andrade RA, Marques TF, Jasper SP, Junior ERD, Fuzitani EJ \& Nomura ES (2011) Micropropagação de mudas de bananeira em meio líquido. Comunicata Scientiae, 2:156-159.

Caldas LS, Haridasan P \& Ferreira ME (1998) Meios nutritivos. In: Torres AC, Caldas LS \& Buso JA (Eds.) Cultura de tecidos e transformação genética de plantas. Brasília, EMBRAPA. p.87-132

Camolesi MR, Faria RT, Neves CSVJ \& Martins AN (2010) Volume do frasco e consistência do meio de cultura na multiplicação in vitro da bananeira 'Maçã'. Ciência Rural, 40:255-260. 
Carvalho ACPP, Rodrigues AAJ \& Santos EO (2012) Panorama de produção de mudas micropropagadas no Brasil. Fortaleza, Embrapa Agroindústria Tropical. 42p.

Carvalho ACPP, Santos EO \& Rodrigues AAJ (2011) Panorama da produção de mudas micropropagadas no Brasil. In: Gerald LTS (Org.) Biofábrica de plantas: produção industrial de plantas in vitro. São Paulo, Atiqua. p.380-393.

Cidade DAP, Garcia RO, Duarte AC, Martins GS \& Mansur E (2006) Morfogênese in vitro de variedades brasileiras de canade-açúcar. Pesquisa Agropecuária Brasileira, 41:385-391.

Costa FHS, Pereira MAA, Oliveira JP \& Pereira JES (2007) Efeitos de agentes geleificantes alternativos no meio de cultura no cultivo in vitro de abacaxizeiro e bananeira. Ciência e Agrotecnologia, 31:41-46.

Debiasi C, Zaffari GR, Salerno AR \& Guerra MP (2002) Correlação entre a capacidade proliferativa in vitro e a dominância apical in vivo da bananeira cvs. Grand Naine e Nanicão. Revista Brasileira de Fruticultura, 24:597-600.

Ferreira DF (2010) SISVAR - Sistema de análise de variância. Versão 5.3. Lavras, UFLA. CD-ROM.

Fortes GRL \& Pereira JES (2001) Estabelecimento in vitro da ameixeira cv. América. Revista Brasileira de Fruticultura, 23:183185 .

Grattapaglia D \& Machado MA (1998) Micropropagação. In: Torres AC, Caldas LS \& Buso JA (Eds.) Cultura de tecidos e transformação genética de plantas. Brasília, SPI/ EMBRAPA. p. $183-260$.

Lemos EEP, Ferreira MS, Alencar LMC, Oliveira JGL \& Magalhães VS (2001) Micropropagação de clones de banana cv. Terra em biorreator de imersão temporária. Revista Brasileira de Fruticultura, 23:482-487.

Mehrotra S, Goel MK, Kukreja AK \& Mishra BN (2007) Efficiency of liquid culture systems over conventional micropropagation: A progress towards commercialization. African Journal of Biotechnology, 6:1484-1492.
Mengarda LHG, Povoas L, Debiasi C \& Pescador R (2009) Estado físico do meio de cultura na propagação in vitro de bromeliaceae. Scientia Agraria, 10:469-474.

Muhammad A, Rashid H \& Hussain I (2007) Proliferation-rat e Effects of BAP and Kinetin on Banana (Musa spp. AAA Group) 'Basrai'. HortScience, 42:1253-1255.

Murashige T \& Skoog FA (1962) Revised medium for rapid growth and bioassays with tobacco tissue cultures. Physiologia Plantarum, 15:473-497.

Oliveira MKT, Neto FB, Câmara FAA, Nunes GHS \& Oliveira FA (2007) Propagação "in vitro" da cultura do abacaxizeiro ornamental (Ananas lucidus Miller). Caatinga, 20:167-171.

Penchel RM, Otoni WC \& Xavier A (2007) Tecnologia de biorreatores e propagação fotoautotrófica in vitro. In: Borém A (Ed.) Biotecnologia Florestal. Viçosa, UFV. p.75-92.

Pereira FD, Pinto JEBP, Rodrigues HCAR, Rosado LDS, Beijo LA \& Lameira OA (2006) Proliferação in vitro de brotos de curauá utilizando diferentes volumes de meio de cultura. Plant Cell Culture \& Micropropagation, 2:102-106.

Pereira JES \& Fortes GRL (2003) Protocolo para produção de material propagativo de batata em meio líquido. Pesquisa Agropecuária Brasileira, 38:1035-1043.

Roels S, Escalona M, Cejas I, Noceda C, Rodriguez R, Canal MJ, Sandoval J \& Debergh P (2005) Optimization of plantain (Musa AAB) micropropagation by temporary immersion system. Plant Cell, Tissue and Organ Culture, 82:57-66.

Siqueira DL, Santos D, Salomão LCC, Silva FF \& Barros ZJ (2013) Micropropagação da bananeira 'Maçã', cultivada in vitro em diferentes volumes de meio líquido. Revista Ceres, 60:745-751.

Ulisses C, Willadino L, Albuquerque CC \& Câmara TR (2010) Clonagem Vegetal. Anais da Academia Pernambucana de Ciência Agronômica, 7:86-91. 